\title{
XXIX. On the time-integral of a transient electromagnetically induced current
}

\section{Sir William Thomson F.R.S.}

To cite this article: Sir William Thomson F.R.S. (1890) XXIX. On the time-integral of a transient electromagnetically induced current, Philosophical Magazine Series 5, 29:178, 276-280, DOI: $10.1080 / 14786449008619936$

To link to this article: http://dx.doi.org/10.1080/14786449008619936

曲 Published online: 08 May 2009.

Submit your article to this journal $[\pi$

Џ Article views: 3

Q View related articles $₫$ 
seriously interfere with that from the front, but also no doubt to reflexions from points situated in the substance of the glass. A sheet of glass two centimetres thick gives fairly good reflexion, while a sheet of paraffin of that thickness would give almost no effect.

Thus by using glass it was comparatively easy to obtain stationary waves by reflexion from a small surface of a nonconducting substance, in order to compare the effect thus produced on the position of the stationary waves with that produced by employing a small metallic reflector. The first node was found to be shifted out nearly $\frac{1}{8} \lambda$, as in the case of metallic reflexion. That reflexion from glass is not of the metallic sort was proved by obtaining polarized reflexion. In this case the two opposite edges of the nonconductor may be looked apon as undergoing variations of apparent electrification.

\section{On the Time-integral of a Transient Electromag- netically Induced Current. By Sir WinLIaM Thomson, $F . R . S . *$}

$\mathbf{I}^{\mathrm{T}}$

T has hitherto been generally supposed that, in ordinary soft iron, the oppositely directed induction, with or without secondary circuit, induced by startings and stoppings of current in the primary circuit, have equal time-integrals.

I have recently perceived [been wrongly led to imagine] that this may be far from being practically the case by the following considerations. The starting and stopping of the current in the primary circuit was, in Faraday's original discovery of this kind of electromagnetic-induction (Exp. Res. Series I. Nov. 1831), and is generally in elementary illustrative experiments, produced by making and breaking a circuit consisting of a voltaic element or battery and the inductor-wire. In this arrangement the starting of the induetor-current is generally much less sudden than the stopping. Hence a thicker shell of the secondary wire (or portion inwards from the outward boundary) is utilized for conducting the secondary current, on the make, than on the break $\uparrow$. Hence the effective ohmic resistance in

* Communicated by the Author.

+ [In reality the $w$ hole cross sectional area of the secondary conductor is utilized, equably in all its parts, in conducting the secondary current. See Postscript of February 23.] 
the secondary circuit is less to the current induced by the make than to the current induced by the break; and the time-integral of the former current is correspondingly greater than the time-integral of the latter.

Faraday in his first experiment found the current induced by the make to be greater than that induced by the break, but he explained it by the running down of his voltaic battery during the time the current was passing through the primary, in consequence of which the magnitude of the current stopped on the break was smaller than that of the current instituted on the make. This was undoubtedly a vera causa, and probably one of considerable potency, considering that Faraday had then no Daniel's battery and had no storage-cells to serve him in his work. Another vera causa is the heating of the circuit, which, even with a battery of constant E.M.F., may render the current started very considerably greater than the current stopped in ordinary experiments. Faraday, in his original experiments*, had only magnetization of steel wires to discover the induced currents by, and to test their magnitude; and he had no galvanometer in the primary circuit. If he had had a ballistic galvanometer in his secondary circuit, and any suitable galvanometer for steady currents in his primary circuit, he might possibly have found that the time-integral (as shown by the ballistic galvanometer) of the primary current exceeded that of the secondary current by a greater difference than could be accounted for by the current being suddenly started and the current suddenly stopped in the primary. So far as I know no one, from 1831 till now, has made any experimental examination of the question suggested in Faraday's Exp. Res. Series I. 16 ; and his idea that the two currents are equal has been generally accepted $\ddagger$. I have therefore asked Mr. Tanakadaté to make some experiments on the subject in my laboratory. He immediately obtained results $\S$ seeming to demonstrate a con-

* Exp. Researches, Series I., 1831.

$+[$ No. On the contrary, he would have found that his first idea, of perfect equality of the two currents, was perfectly true! February 23.]

$\ddagger$ See Maxwell's 'Electricity and Magnetism' (1873), vol. ii. \$537, p. 171.

$\S$ But these results we find are quite untrustworthy because of the susceptibility of the steel needle of the galvanometer to magnetic induction, which with the currents produced through its coil by the induced currente due to the make and break in the primary eircuit, may largely alter its effective magnetism. It is in fact well known that ballistic galvanometers with steel needles give very erratic results if they are used in attempting to find time-integrals of very intense transient currents of very short duration. 
siderable excess in the time-integral (as shown by a ballistic galvanometer) of the secondary current on the make above that on the break. A magneto-static galvanometer in the primary circuit showed the current before the break to be always a little less than immediately after the make. This difference was due to heating of the primary circuit, because a potential galvanometer applied to the two terminals of the voltaic element used, which was a large storage-cell, showed no sensible drop of potential during the flow of the current in the primary circuit. It was, however, insufficient to account for the large differences found between the ballistic deflexions produced by the induced currents on the make and on the break. A rapid succession of makes and breaks has given large irregular permanent deflexions of the ballistic galvanometer, sometimes in one direction, sometimes in the other, which we bave found to be chiefly due to magnetic susceptibility of the steel needle of the ballistic galvanometer: and we find that this cause has probably vitiated the observations on the effects of single makes and breaks. I have therefore arranged to have experiments continued, with a coil of very fine wire bifilarly suspended, instead of the steel needle of the ballistic galvanometer; a steady current through the fine wire being maintained by an independent voltaic battery.

Hitherto the make and break have been performed by hand, dipping a wire into and lifting it out of a cup of mercury.

Various well-known methods may be used to render either the break or the make so gradual that we may be sure of the induced current running practically full-bore through the secondary. On the other hand, very sudden breaks may be effected by separating two little balls or other convex pieces of copper by the blow of a hammer. The experiment may be varied by short-circuiting the ends of the inductor and allowing the current from the battery to continue flowing through electrodes of sufficient resistance not to allow an injuriously great amount of current to flow. These electrodes, between the voltaic element and the ends of the inductor-wire, may have large self-inductance given to them by coiling them round a closed magnetic circuit of soft iron. The starting of the current in the inductor-wire will thus be rendered much more sudden than the stopping; and the induced current in the secondary will no doubt be found stronger on the stoppage than on the start. Mr. Tanakadaté is continuing the experiments with these modifications in view.

The mathematical foundation of the common opinion that 
the time-integrals of the induced currents on the make and break are equal is as follows*.

Let $\beta$ and $\gamma$ be the currents at time $t$ in the primary and in the secondary circuits respectively; $J$ the self-inductance of the secondary circuit; and $M$ the mutual inductance of the two. We have

$$
\mathrm{R}_{\gamma}=-\mathrm{M} \frac{d \beta}{d t}-\mathrm{J} \frac{d \gamma}{d t}
$$

Hence if $\gamma=0$ when $t=0$, and if we suppose $\mathrm{R}$ to be constant,

$$
\int_{0}^{t} \gamma d t=\frac{\mathbf{M}}{\overline{\mathbf{R}}}\left(\beta_{0}-\beta\right)-\frac{\mathrm{J}}{\overline{\mathrm{R}}} \boldsymbol{\gamma}
$$

Now let T be any value of $t$ so large that $\beta$ has become sensibly constant, and $\gamma$ has subsided to zero. We have

$$
\int_{0}^{\mathrm{T}} \gamma d t=\frac{\mathrm{M}}{\mathrm{R}}\left(\beta_{0}-\beta_{\mathrm{T}}\right) .
$$

This shows that the time-integral of the induced current in the secondary circuit would depend solely on the difference of values of the current in the primary at the beginning and end of the time included in the reckoning, and would be quite

* February 23. - Worked out more perfectly it shows, as follows, that the common opinion is correct!

Imagine the whole secondary conductor divided into infinitely small filaments of cross-section $d \Omega$ : and let $\xi$ be the current-density, at time $t$, in any one of these. Instead of $\gamma$ in the text take $\xi d \Omega$, and instead of $\mathrm{R}$ take $l /(\sigma d \Omega) ; \sigma$ denoting the specific conductivity of the material, and $l$ the length of the circuit. We have

$$
l_{\sigma^{-1}} \xi=-\mathrm{M} \frac{d \beta}{d t}-\mathrm{J} \frac{d \xi d \Omega}{d t}-\mathrm{S}
$$

where $S$ denotes the sum of effects due to the risings and fallings of current in the different parts of the secondary conductor. Their time-integral from 0 to $T$ is essentially zero; as is also that of the infinitesimal middle term of the second member. Hence we have

$$
l \sigma^{-1} \int_{0}^{\mathrm{T}} d t \xi=\mathrm{M}\left(\beta-\beta_{0}\right)
$$

which shows that the time-integral of the current, $\xi d \Omega$, in each filament of che socondary conductor, is exactly equal to that which is calculated according to the ordinary elementary theory! The whole details of the fallacy in the text are now clear !] 
independent of suddennesses, if the effective olmic resistance were constant. But this supposition is not true; and that it is very effectively untrue for copper wires of a millim. diameter or more, and times of change in the primary less than $\overline{3} \frac{1}{3}$ of a second, we see readily by looking to the diffusional curve and the time-number, $\frac{1}{20}$ of a second for curve 10 , corresponding to the diffusivity of copper for electric currents (which is 131 square centimetres per second) given and explained in my short article on a Five-fold Analogy, in the British Association Report for Manchester, 1888 (to be found also in the Electrical Journals, and 'Nature').

[Postscript, February 23, 1890.-The thermal analogy, which is very simple for the case of electric currents in parallel straight lines, has, as soon as I have considered it, shown me the fallacy pervading the text; and has led me to make the corrections in the insertion and footnotes enclosed in brackets [ ], all of which are of the date of this postscript. Preliminary experiments with the suspended coil instead of the steel magnet, in a ballistic galvanometer now nearly completed by Mr. Tanakadaté, have already disproved the large differences which I expected between the time-integrals of the secondary currents on the break, and on the make; and as far as they have yet gone are consistent with the perfect equality which I now find proved by theory.]

\section{Proceedings of Learned Societies.}

GEOLOGICAL SOCIETY.

[Continued from p. 135.]

December 18, 1889.-W. T. Blanford, LL.D., F.R.S., President, in the Chair.

THE following communications were read :-

1. "On the Occurrence of the Genus Girvanella, and remarks on the Oolitic Structure." By E. Wethered, Esq., F.G.S.

2. "On the Relation of the Westleton Beds or 'Pebbly Sands' of Suffolk to those of Norfolk, and on their extension inland, with some observations on the Period of the final Elevation and Denudation of the Weald and of the Thames Valley."'-Part II. By Prof. Joseph Prestwich, M.A., D.C.L., F.R.S., F.G.S.

The author having, in the first part of this paper*, discussed the relationship of the Westleton Beds to the Crag Series and to

* Phil. Mag. [5] xurviii, p. 142. 